\title{
Normative and Descriptive Aspects of Management Education: Differentiation and Integration
}

\author{
Gavriel Meirovich (Corresponding author) \\ Department of Management, Bertolon School of Business, Salem State University \\ 352 Lafayette Street, Salem, MA 01930, United States
}

Tel: 978-543-6948 Fax: 978-542-6027Ｅ-mail: gmeirovich@salemstate.edu

\begin{abstract}
Received: April 7, 2015 Accepted: May 27, 2015 Published: June 3, 2015
doi:10.5296/jei.v1i1.7395 URL: http://dx.doi.org/10.5296/jei.v1i1.7395
\end{abstract}

\begin{abstract}
This study advocates strongly for clear differentiation and synthesis of descriptive and normative approaches in management education. There is a certain isolation of normative and descriptive theoretical frameworks presented in management courses. Normative frameworks in management explain how organizations should be managed, while descriptive frameworks show how they actually are managed. Significant portions of what we teach in the business curriculum are predominantly descriptive; other parts are mostly normative, or prescriptive. If these domains are not sufficiently connected, the relevance of both approaches diminishes. When one piece of material explains only the current reality without providing tools to improve it, while another piece prescribes steps for improvement that are not grounded in a particular context, students lose interest in both. The paper presents various modes of differentiation and integration between two realms and pertinent ways to recalibrate management courses.
\end{abstract}

Keywords: Normative and descriptive framework, Differentiation, Integration

\section{Introduction}

The purpose of business education is preparing future business professionals for successful careers and meaningful lives. The continued rise of its cost poses difficult questions about the relevance of contemporary business education in general and management education in particular. One of the core issues in this regard is the relevance of theoretical models taught in business schools. While at college students are exposed to numerous theoretical frameworks which are supposed to be applied in some way in practice. Yet both formal and informal encounters with students that had studied management courses such as Organizational Behavior, Principles of Management, Introduction to Business, etc. have brought me to the 
disquieting conclusion that most of them could not recollect most of the models learned in these courses. For instance, while teaching senior level Management Seminar course I tried to relate class discussions to previously studied models of motivation, leadership, organizational structure etc. With a few exceptions most of participants did not remember them. It goes without saying that the memorization of theories is not an end in itself. Nevertheless, content knowledge is indispensable, and it is hard to imagine how someone can apply theories without possessing at least some awareness of them.

One possible contributing factor to this problem is a certain isolation of normative and descriptive theoretical frameworks presented in management courses. Normative frameworks in management explain how organizations should be managed, while descriptive frameworks show how they actually are managed. If these domains are not sufficiently connected, the relevance of both approaches diminishes. When one piece of material explains only the current reality without providing tools to improve it, while another piece prescribes steps for improvement that are not grounded in a particular context, students lose interest in both.

Consider the instance of rational and administrative models of decision-making. The former is regarded as a normative model, the latter as a descriptive one. Thus the first theory explains how good decisions should ideally be made, whereas the second describes how less than optimal decisions are in fact made. Placing myself in the shoes of students, I wonder how exactly this knowledge would be helpful for me. One model sketches an ideal but unachievable state, while another model realistically depicts a 'gray' situation without showing ways to ameliorate it. The value of both approaches will be augmented if we can integrate them in some framework that is both realistic and provides a roadmap for enhancement of actual conditions.

Significant portions of what we teach in the business curriculum are predominantly descriptive. One vivid example is the course Introduction to Business, which includes a lot of disparate data, facts, terms, and narratives depicting the realities of contemporary businesses. As an instructor I have to put a considerable effort so that students attending this course are not overwhelmed by the amount and heterogeneity of material. When descriptions of various aspects of business follow close on one another, students experience information overload by receiving information they might perceive as excessive, or, putting it more bluntly, as informational noise.

Other parts of the business curriculum are mostly normative, or prescriptive. They entail topics such as ethical principles; normative model of decision-making; cultural values, visionary and servant leadership models, etc. If normative claims have no foundation in students' perceived reality, the generally 'good' principles become too abstract and elicit an "it's good in theory, but not applicable her" responses. As Donaldson and Dunfee (1994: p. 260) argue, a course in business ethics that never moves beyond a discussion of abstract universal normative principles is doomed to disaster. Why would results be significantly different in other fields of management?

Both descriptive and normative approaches taken separately are one-sided, resulting in low value, or, using the terminology of Vroom's (1964) expectancy theory, low valence for 
students, and as a result are not appealing to them. The low value of content pushes students to grade-seeking behavior (Meirovich \& Romar, 2007), where the guiding motivation for learning certain theoretical material becomes an expected grade rather than the acquisition of practical knowledge. This problem is exacerbated by the lack of clear discrimination between the normative and descriptive realms in most areas of management theory. The only fields where the distinction between normative and descriptive approaches is made explicit are business ethics and, to a certain degree, decision-making. Yet even in these areas differentiation is not coupled sufficiently with synthesis. Scholars in business ethics have long recognized that the two dimensions gain significance only in connection with each other, and that it is essential to find synergy between them (Rosenthal \& Buchholz, 2000; Victor \& Stephens, 1994).

In other fields it is quite common that normative and descriptive constructs are presented in the same educational text in a mixed format without distinct indication which domain they belong to. In order to increase the relevance of theoretical frameworks studied in management, there should be a deliberate differentiation between normative and descriptive elements followed by their integration. Addressing relationships between two realms, we have to examine certain questions that are presented in subsequent sections of this paper.

\section{Theoretical Framework - Descriptive or Normative?}

When we encounter any theoretical framework or construct, the first question to be asked is whether this framework is normative or descriptive. For instance, the concept of deviation is normative, since it implies the existence of a certain standard and a mismatch between it and actual behavior. The concept of variation can be used as both normative and descriptive depending on context. In contrast, variety is a more descriptive term because it involves acceptance of differences that are not necessarily seen through a better/worse lenses.

In the literature, a recognition of the two approaches usually takes place on the macro level, i.e. on the level of a model or theory as a whole. One prominent example to which I previously alluded is the difference between models of decision-making. The rational model is considered a normative framework; the pattern managers should use it in order to make better decisions. The administrative model involving bounded rationality and 'satisficing' rather than 'maximizing' is presented as a descriptive framework, the way managers are making decisions in reality. The same goes for the political model of decision-making (Daft, 2014). But it is also possible to so to speak increase "the resolution" of lenses and to distinguish between normative and descriptive components on the micro level, i.e. within the same theoretical framework. That will allow us to define descriptive elements in the rational model and normative elements in the administrative or in the political model of decision-making. The former would involve conditions or contexts in which this approach is feasible: transparency condition (Bell, Raiffa, \& Tversky, 1988); consensus on goals, absence of biases, complete information, and absence of time and cost constraints (Daft, 2014; Robbins \& Coulter, 2013). In turn, administrative and political models have certain normative components. In the administrative model one should use trial-and-error process rather than be carried away by escalation of commitment; treat errors as useful experiments with negative 
results, etc.; in the political framework one should identify sources of power, and build a coalition with sufficient clout etc.

In general, a normative framework involves the following components:

1) Presence of a standard such as a value, norm, rule, goal, best practice, or principle. By creating a standard that should be met, the normative approach provides structure and decreases the amount of discretion of the parties involved.

2) Evaluation, judgment of current situation/performance - whether or not there is deviation from standards in actual situation and what the extent of deviation is.

3) Prescriptive part - measures designated to close the gap between a standard and current performance in case such a gap exists.

In turn, standards can be characterized by several dimensions:

A) Quantity. There can be many as opposed to few or even non-existent standards, e.g. many rules resulting in high formalization vs. few rules resulting in low formalization. Another example is the managerial system of Management by Objectives (MBO) in which the number of objectives for employees is an important issue. Too small a number of objectives might leave certain aspects of performance without proper attention ("What gets measured gets done"); too large a number of objectives on the other hand can be detrimental to the efficiency of the MBO since it does not allow focusing on the most important performance areas.

B) Power. Standards can be strong or weak. Stronger standards involve smaller tolerance, or acceptable range of variation. An example can be strength of organizational culture characterized by strong or weak values and norms. Another instance of strong standards can be rigid rules resulting in coercive formalization (Adler \& Borys, 1996). An extreme case would be a totalitarian system which does not tolerate any deviation from prescribed conduct. An extreme case on the other end, when standards are too weak or nonexistent, would be 'anything goes' relativism (Weaver \&Trevino, 1994) resulting in utter uncertainty and lawlessness.

C) Fairness (e.g. impartially administered rewards vs. double standards, nepotism and discrimination).

D) Feasibility (e.g. realistic vs. unrealistic goals/objectives).

E) Specificity (e.g. specific vs. general goals/objectives).

F) Acceptability. Some standards are more acceptable to involved parties than others. For instance, in a strong culture, shared values and norms make rules redundant; any rule contradicting these norms would be ignored; the same happens when authority is not perceived as legitimate and is rejected by subordinates.

G) Process-orientation vs. result orientation. Among process-oriented, or instrumental, standards are best practices, rationality in decision-making, instrumental values (e.g. hard 
work and open communication); standing operating procedures. Result-oriented, or terminal standards include terminal values (e.g. high customer satisfaction, high quality); goals, objectives etc.

H) Subjective vs. objective standards. Customer expectation is a subjective standard, while product specification is an objective one.

I) Qualitative vs. quantitative standards. Quality improvement and high customer satisfaction as organizational values serve as qualitative standards, whereas reduction of the percentage of defective products from $1 \%$ to $0.5 \%$ is a quantitative standard.

\section{Differentiation between Descriptive and Normative Domains}

Defining whether a particular construct/framework belongs to normative or descriptive sphere leads to the next question - is there a clear differentiation between these two facets in a certain field of management? The most evident distinction between the two approaches can be seen in the areas of decision-making and business ethics. An example of rational vs. administrative and political models of decision-making was provided earlier. In the field of business ethics there is a clear and well-recognized division between normative and descriptive ethics (Fukukawa, 2003; Rosenthal \& Buchholz, 2000; Trevino \& Weaver, 1994; Werhane, 1994). Normative ethics involves ethical principles - the Kantian principle of the categorical imperative, the utilitarian principle, the Confucian golden rule principle, principles of procedural and distributive justice, etc. These approaches show how decisions ought to be made in order to be judged as ethical. Descriptive ethics reflect actual behavior in organizations. Prominent examples of descriptive models are the theory of stages of personal moral development (Kohlberg, 1976) and the model of modes of managing morality at the organizational level (Rossouw \& van Vuuren, 2003).

In other fields of management such as leadership, motivation, communication, organizational structure, etc., discrimination between normative and descriptive aspects is not clearly articulated. In these areas the distinction is usually made between theoretical models and their application. Although there is a significant overlap between theory-practice and normative-descriptive dichotomies, they are not identical. The closest to the application concept is the prescriptive portion of the normative approach. Yet normative frameworks include other elements - the existence of a standard and evaluation of possible deviations from the standard in real situation. Even between prescription and application there is significant difference. Prescription may include a theoretical portion as well as practical guidelines. Consider need theories of motivation (Alderfer, 1969; Maslow, 1954, McClelland, 1985). Regardless of how they differ in their descriptive portions, they all prescribe to identify and satisfy the dominant needs of individuals in order to enhance their motivation. This common theme of the prescriptive component is still theoretical rather than applicative. The latter would include practical steps designed to satisfy specific needs, e.g., introduction of training and educational programs so as to satisfy high-level, or growth needs.

The field of business ethics can also illustrate the difference between application and prescription. Normative tenets of ethics such as Kantian or utilitarian principles are 
theoretical and prescriptive. Application of these principles requires provision of additional guidelines and practical recommendations which specify concrete measures that managers should take in order to implement these tenets.

If we explore various theoretical frameworks in management from normative-descriptive dichotomy perspective, we can conclude that some of these frameworks implicitly make a distinction between normative and descriptive sides, while others fail to do that. An example of implied differentiation between two aspects is the general model of decision-making process. It involves several steps, the first of which is problem recognition (see, e.g. Robbins $\&$ Coulter, 2013). A problem is defined as the discrepancy between a desired and actual state of affairs. The former in fact represents the normative aspect - the way things should be, while the latter represents the descriptive side - the way things really are. Besides mere identification of two different sides of a gap, it is advisable to address cognitive fallacies that preclude their distinction. Among these phenomena are the so called 'boiled frog effect' (Voloch, 2003), or failure to perceive a gradually increasing problem, and wishful thinking (Bastardi, Uhlmann, \& Ross, 2011), which blurs the difference between desired and current conditions. Awareness of these phenomena reinforces realization of a difference between normative and descriptive sides that later should be bridged.

A similar gap between normative and descriptive sides is represented by other concepts such as environmental uncertainty and emotional labor. The first construct relates to the discrepancy between required and available information in regards to various factors in an organizational task and the general environment (Daft, 2014). The second construct refers to the gap between 'appropriate' and actually felt emotions, and to the psychological effort needed to display socially desired emotions (Hochschild, 1983; Morris \& Feldman, 1996; Samella, 2005).

Another apt example of a model discriminating between the two facets is the GLOBE model (House, Hanges, Javidan, Dorfman, \& Gupta, 2004). It states that every national culture involves two types of behavioral standards - actual, or 'as is' practices and values, and 'should-be' standards. The first type reflects standards of existing behavior in a certain cultural environment, while the second type reflects the standards of desirable behavior. Differentiation between two types of cultural standards constitutes a significant advantage of the GLOBE model over Hofstede's (1985) model of national cultural dimensions. Failure to distinguish between 'should be' and actual norms by the latter model diminishes its theoretical validity and practical value.

Similar drawbacks can be observed in studies on customer expectations. One should distinguish between normative (should) and predictive (will) expectations of customers (Devlin, Gwinne, \& Ennew, 2002; Laroche, Kalamas, Cheikhrouhou, \& Cezard, 2004; Meirovich \& Little, 2014; Voss, Parasuraman, \& Grewal, 1998). Normative expectations constitute customers' beliefs about what a product/service provider should offer and represent standards against which customers compare their perceptions of quality (Parasuraman, Zeithaml, \& Berry, 1985), whereas predictive expectations are experience-based predictions or anticipations of what likely will happen in the future. Still, the lack of distinction between 
normative and predictive expectations is quite common in the literature, which leads to deficiencies in theoretical implications and recommendations for practitioners.

A list of examples of normative and descriptive constructs in various fields of management which does not pretend to be exhaustive is provided in Table 1 .

Table 1. Normative and descriptive constructs

\begin{tabular}{|c|c|c|}
\hline Subjects & Normative phenomena & Descriptive phenomena \\
\hline Business ethics & Ethical principles & Stages of moral development \\
\hline Models of decision-making & Rational decision-making & $\begin{array}{l}\text { Administrative model, } \\
\text { Political model }\end{array}$ \\
\hline Decision-making process & Desired state of affairs & $\begin{array}{l}\text { Actual state of affairs } \\
\text { Causes of problems } \\
\text { Cognitive biases, heuristics in } \\
\text { decision-making }\end{array}$ \\
\hline Uncertainty & Required information & Available information \\
\hline Emotional labor & Displayed emotions & Actually felt emotions \\
\hline Control process & Variation, deviation from standard & Measurement of performance \\
\hline Planning, strategy & $\begin{array}{l}\text { Goals, standards of performance } \\
\text { Process of introduction of procedures }\end{array}$ & $\begin{array}{l}\text { SWOT analysis; } \\
5 \text { forces analysis; } \\
\text { Description of a procedure }\end{array}$ \\
\hline Expectations & Normative expectations & Predictive expectations \\
\hline National Culture & 'Should' norms & 'As is' norms \\
\hline Communication & $\begin{array}{l}\text { Rules of reflective listening, KISS (keep it } \\
\text { short and simple) principle; ways to overcome } \\
\text { communication barriers; need for feedback }\end{array}$ & $\begin{array}{l}\text { General schema of } \\
\text { communication, barriers to } \\
\text { effective communication }\end{array}$ \\
\hline Quality management & Specification (tolerance) limits & Control limits \\
\hline Organizational structure & Balance between authority and responsibility & Authority \\
\hline $\begin{array}{l}\text { Motivation } \\
\text { (model of McGregor) }\end{array}$ & Theory Y & Theory X \\
\hline $\begin{array}{l}\text { Leadership } \\
\text { (model of Managerial Grid) }\end{array}$ & 9.9 Participative style & Existing style \\
\hline
\end{tabular}

Except the first two instances, which represent the macro-level of distinction between normative and descriptive domains, the examples reflect a micro-level of analysis, i.e. elements of a certain model rather than the entire model. Advantage of the micro-approach is 
that it allows us to regard normative and descriptive domains as opposite and conflicting sides of a united whole, to maintain creative tension between the two sides, and eventually to bridge these two realms within the same theoretical framework. Such an approach would make it possible to keep certain models both realistic and authentic on the one hand and instrumental towards improvements on the other. In contrast, the macro-approach separates too strongly between two domains and makes both less appealing. It stops at differentiation without providing synthesis between the two realms.

Differentiation on the micro-level between descriptive and normative sides should be followed by their integration. This logic brings us to the next question in regards to the two approaches - is there a sufficient linkage between descriptive and normative parts in the model?

\section{Integration between Descriptive and Normative Domains}

As emphasized throughout the paper, students' engagement with a content that they study will be increased when two sides are presented in close connection. When such linkage is established, students obtain both a true picture of reality and the conceptual framework needed to improve it. There are several ways in which this linkage is or can be made.

The first and simplest option is to juxtapose current and desired states within the same framework and accurately define the difference, or the gap, between them. The previously alluded to concepts of problem definition, uncertainty and emotional labor suit this subcase. Collocation of actual and normative conditions demonstrates absolute distance between two domains. Objective assessment of this discrepancy does not provide a solution yet, but serves as an important initial step towards a solution.

Unlike the gap format, other models indicate the degree, or extent, of fit (or misfit) between normative and descriptive aspects. For instance quality management uses the metric of process capability. Its formula is the following (Gitlow, Oppenheim, Oppenheim, \& Levine, 2005):

$$
C_{p}=\frac{U S L-L S L}{U C L-L C L}
$$

Where, USL and $L S L$ are upper and lower specification limits; $U C L$ and $L C L$ are upper and lower control limits.

Specification limits constitute a standard against which the process is measured. The distance between these two limits characterizes tolerance, i.e. the range of acceptable variation. If a product finds itself within this range, it is considered an apt one; if it is outside specification limits it is considered a defective one. In contrast, control limits characterize real variation of the process. They are calculated as a mean of the process plus/minus 3 standard deviations. The whole formula demonstrates the ability of a process to produce products that are in good working order. If $\mathrm{Cp}<1$, the process is inadequate; if $\mathrm{Cp}>1$, it is appropriate; and if $\mathrm{Cp}=1$, it is considered borderline (Evans \& Lindsay, 2008; Gitlow et al., 2005). The numerator of the formula belongs to the normative realm, while the denominator belongs to the descriptive 
realm; comparison between them demonstrates to what extent these realms match.

Another, less quantifiable example is the model of Donaldson and Dunfee (1994) of bounded moral rationality. Following Simon's (1991) concept of bounded rationality in decision-making, the authors define three types of limits to rationality in business ethics: limited human capacity to assess facts, finite capacity of ethical theory to capture moral truth, and the artifactual nature of economic systems (ibid, p. 258). Ethical rationality is a normative construct, whereas types of bounds are real, that is, they are descriptive constructs; the stronger the bounds, the lower the degree of fit between two domains. Similar logic of defining degree of applying of normative principle can be observed in Victor and Cullen's (1988) model of organizational ethical climate, which describes the degree to which a certain normative ethical principle is actually applied, and the degree of agreement on a particular principle in practice. Again, the larger the extent of practice of one or another principle, and the larger extent of agreement, the larger the overlap between normative and descriptive domains.

A second type of linkage is provided in models that belong to a situational or contingency approach. Contingency models were developed in areas of organizational structure (e.g. mechanistic vs. organic structures (Burns \& Stalker, 1961), levels of centralization, and formalization (Blau \& Schoenherr, 1971; Mansfield, 1973)); leadership (models of Fiedler (1967), Hersey-Blanchard's (2013) SLT theory, path-goal theory (House, 1996)); decision-making (model of Vroom-Jago (1988) on participation in decisions), etc. Such models identify certain contextual factors that moderate outcome variables.

Contingency factors can be environmental (stable vs. dynamic environment); organizational (size, strategy, technology); personal (employees' abilities, locus of control, willingness); or position-related (task structure, position power). They depict specific situations and thus pertain to the descriptive domain. In turn, the concept of fit (or misfit) is evaluative, i.e. normative. It implies the presence of a certain standard (e.g. apt leadership style), and deviation from this standard. Outcome variables (e.g. creating organic or mechanistic structures depending on the relative stability or instability of the environment; introducing a degree of decentralization and formalization due to the organization's size; using a particular style of leadership basing on employees' readiness, etc.) are prescriptive. Contingency models can be framed in an 'if-then' format: if a certain condition is taking place (descriptive part) then one should respond with certain steps (normative part). This format properly grounds normative measures in a particular reality, provided contextual variables accurately predict behavior of outcome variables.

By contrast, models that belong to one best-way paradigm do not identify situational factors moderating dependent variables. Although such models as Managerial Grid (Blake \& Mouton, 1985), Theory X and Y (McGregor, 1961) clearly differentiate between existing and desired conditions, they are too general in their prescriptions. As a result of their "one size fits all" approach, the prescriptive power of such models is diminished. In another instance, the traditional view that span of control (span of management) should include a number of subordinates in the vicinity of seven is too simplistic and general. It disregards specific 
factors that impact span of control - means of communication, physical distance, skills and motivation of employees, etc. In turn, taking these contingency factors into consideration makes the prescriptive part in determining span of control more realistic.

Since contingency frameworks have an "if (descriptive) - then (normative)" pattern, both parts of the equation ought to be presented in textbooks and teaching materials in conjunction. In this way they would mutually reinforce each other and maintain content validity for students. When, by contrast, these descriptive and normative components are presented separately without emphasizing their connection, the valence of both parts is reduced. For instance, in most textbooks on management, environmental uncertainty is explained in the chapter on Organizational Environment, usually located in the beginning of the book, while the topic of mechanistic vs. organic organizations as a normative response to uncertainty is covered in the chapter on Organizational Structure, located in the second half of the book. Thus descriptive and prescriptive parts of the model find themselves in different parts of the text. Concluding the topic of environmental uncertainty without addressing possible application of this theoretical knowledge disconnects two dimensions and makes this content less relevant for students. To overcome this limitation it is preferable to present the concepts of mechanistic and organic organizations as an adaptation to stable or dynamic environment in conjunction with environmental uncertainty. The closer the prescriptive part to the descriptive in course material, the better.

Another type of linkage between the two domains occurs when normative and descriptive elements are 'nested' inside one another so they can be regarded modules of the same compound theoretical framework. Consider the general model of control process which includes the following steps: a) defining standards; b) comparison between standards and performance; c) taking corrective action as long as there is deviation from standards. In this model there are both normative and descriptive components (modules). Defining standards and the comparison of performance with those standards are obviously normative elements. At the same time comparison between standards and performance implies measurement of performance itself, which is the descriptive component of the process. Essential part of the corrective action is the analysis of causes of deviation. Causes exist in reality, therefore they pertain to the descriptive domain, while corrective action is normative - one should analyze causes of variation and take practical steps to close the loop. The whole model has a clearly prescriptive nature - it demonstrates the way control process should be undertaken rather than how it is carried out in reality.

The last in our list, and the most common type of linkage, is provided when a mainly descriptive theoretical model is followed by a discussion of its theoretical and practical implications. A salient example for this type of connection is the Job Characteristic Model (JCM) of Hackman and Oldham (1980). It identifies 5 dimensions of job content that have a potential to impact a person's motivation -skill variety, job identity, job significance, autonomy, and feedback. This part of the theory assesses existing conditions, is thus descriptive. It is logically followed by clear and well-grounded prescriptions for enhancing the motivational potential of certain jobs through job enlargement, job enrichment, rotation, establishing feedback channels, etc. 
In other theoretical models in the field of motivation, the normative approach does not constitute an integral part of the model, so the task of an instructor is to provide this normative follow-up. For instance, expectancy theory (Vroom, 1964) includes three descriptive variables - expectancy, instrumentality, and valence. Presentation of the model should not stop with explanation of these factors; it needs be followed by guidelines, clarifying how to improve each component. This portion of model presentation would be normative.

Many models in other fields of management do not include prescriptive portion. Consider Mintzberg's (1971) model of managerial roles. It is possible to agree with Mintzberg that his ten roles of a manager more correctly describe managerial work than the traditional model of four managerial functions - Planning, Organizing, Leading, and Controlling. The basis for this assertion is that Mitzberg's model was developed based on direct observation of managers in the field. The results of this observation did not fit the four traditional functions of management. One important conclusion of Mintzberg's research was that managers need to switch frequently from one activity to another in a rather unpredictable, unplanned fashion. An accurate and insightful description of real managerial situations is undoubtedly the main value of discussed model. When, during class discussion, I ask graduate students to recognize managerial roles they perform in their actual work, students are genuinely interested and forthcoming in their responses. The model creates deeper understanding of participants' current circumstances by giving correct 'names' and clarifying their day-to-day activities. Still, knowledge of a current situation in itself does not provide tools that would allow one to change existing conditions. Donaldson and Dunfee (1994) warn against the naturalistic fallacy, which is an effort to deduce 'ought to' from 'is'. Mintzberg's model is stronger in its descriptive than in its prescriptive aspect. In order to correct this shortcoming additional steps are warranted.

Such steps might involve an exercise involving: a) students' ranking of the importance of the ten roles in their actual work; b) students' ranking of their skills in performing these roles; c) comparison between the rankings and identifying mismatches between the significance of a role and the level of students' skills. A high rating in terms of importance along with a low skills rating for a particular role would imply that an individual needs to develop skills in order to perform this role properly; the opposite situation would mean 'overkill' - high skills exercised in the performance of peripheral activities.

Another example of a dearth of the normative aspect can be the concept of specialization as a component of organizational structure. Textbooks provide an explanation of a given concept itself, along with the advantages and disadvantages of narrow vs. broad specialization. The prescriptive portion is typically lacking, which leaves students with a more or less accurate depiction of the possible situations in organizations but does not provide necessary tools that would allow them to make improvements in such situations. The same is true in regards to descriptive constructs in decision-making for instance, programmed vs. nonprogrammed decisions. Mere explanation of these constructs even if it concludes yet again with the observation that they describe a real situation, will leave students wondering what exactly they can do in the field with this knowledge. For example, if an individual realizes that he or 
she just made a programmed decision at work, how exactly does that realization help him or her? An instructor should not stop with explanations of constructs themselves; he/she ought to be focused on identifying and delivering the instrumental portions of a theory. In regards to types of decisions, one practical tip can be that when management chooses to decentralize decision-making in a company, it ought to start with programmed decisions. Thus, when a senior manager makes a programmed decision, he or she should probably ask - can this decision be delegated to somebody lower in the hierarchy while I concentrate on nonprogrammed strategic decisions?

\section{Relative Strength of Descriptive and Normative Components}

The last question to be considered in regards to two approaches involves a case in which both descriptive and normative parts of a framework are present - are they equally solid and robust? Is descriptive part evidence-based and insightful? Is the normative aspect realistic, that is, grounded in theoretical and empirical evidence, or does it consist of exhortations, speculation and opinion?

Features of a strong descriptive framework include the following:

$>$ Abstract concepts ("names") capturing the essentials of reality while omitting unnecessary details;

$>$ Connections between constructs rather than just a collection of them;

$>$ Analysis of root causes of empirical phenomena;

$>$ Statements that are evidence-based rather than opinion based or speculative;

$>$ Predictability of future events;

> Vivid stories, which are usually memorized easier than theoretical material; cases that help students to internalize content due to their generalizability;

Negative features of weak descriptive content - by contrast - would involve superficial description on a phenomenological level; arguments and conclusions based on mere common sense or conventional wisdom; excessive details, numbers, PPT ("killing by PPT") which are difficult to remember; constructs presented in unrelated fashion that are difficult to make sense of. Some features from this list can be found in management textbooks.

For instance, one prominent text on strategic management (Thompson, Peteraf, Strickland, \& Gamble, 2014) describes strategic concepts using the following numbers: 8 potential market opportunities, 12 industry's driving forces of change; 12 external threats, 13 potential organizational strengths; 13 potential weaknesses, etc. The previous edition of this textbook included 31 common types of key success factors (Thompson, Strickland, \& Gamble, 2013). Even if authors and instructors using this text and supporting PPT do not intend for students to remember all or most of these attributes, the numbers can seem overwhelming. Some of these features could be combined, while less critical cases could be omitted so that student would be able to focus on really key features.

Quite often textbooks do not show connections between concepts. Examples of this deficiency in descriptive narratives can be found in most books on principles of management 
addressing the subject of planning. Such books typically contain different types of plans presented one after another without revealing connection between them. A student is supposed to comprehend concepts of strategic vs. tactical (operational) plans, specific vs. directional plans, and single-use vs. standing plans in isolated fashion (see e.g. Robbins, De Cenzo, \& Coulter, 2015). It would be preferable to point out that all these dichotomies are connected and that for instance annual budget is a short-term, specific and operational plan, while procedure is an example of an operational standing plan that is not time-bound. It would be even more desirable to show the logical connection between strategic and operational plans - that the latter should stem from the former. Yet, in another textbook, concepts of single-use and standing plans (subtypes of operational plans) are presented before the concept of strategy (Daft, 2014), completely obscuring this link.

In turn, a strong normative portion involves:

$>$ Reasonable and fair standards such as SMART goals;

$>$ Avoidance of excessive standards;

> Both terminal and instrumental standards, i.e. standards that address both ends and means;

> Prescriptions based on a valid theoretical foundation.

Conversely, it is quite typical for popular books on management to include long lists of prescriptions that are detached from analysis of real organizational circumstances and are therefore hardly applicable. Examples of deficiencies in normative approach can be seen in many texts on practical managerial systems such as MBO, TQM and Six Sigma. Quality management guru E. Deming criticized MBO for not providing necessary means to reach declared goals (Deming, 1986). Although not all applications of MBO suffered from such deficiency, many did. One of the principles of TQM formulated by Deming is that of avoiding empty slogans and exhortations (ibid). Vareman (2008) points out that when a normative approach defines goals alone without the guidelines on how to achieve them, it becomes speculative. These points are valid, but a similar critique can be made of TQM itself. Many applications of quality management failed because of disconnects between lofty tenets and cultural and institutional context. TQM prescriptions are often presented in one-best way fashion, are too general, and suffer from lack of contingency approach. They disregard moderating variables such as organizational culture, impact of unionization, competitive strategy, level of uncertainty and others (Jayaram, 2010; Meirovich, 2006; Sitkin, Sutcliffe, \& Shroeder, 1994).

It is not uncommon that textbooks illustrate positive managerial phenomena without examining conditions when such positivity is feasible. For instance, reading texts on servant, level 5 and moral leadership (see e.g. Daft, 2014) that are purely normative and prescriptive leaves one with an uneasy feeling that implementation of these outstanding styles would involve significantly more challenges and conditions than are mentioned in the text. Illustrations by real examples of business leaders using these styles are helpful, but insufficient because these positive examples might not be generalizable to other situations. 


\section{Conclusion}

This study advocates strongly for clear differentiation and synthesis of descriptive and normative approaches in management education. Except for the fields of business ethics, and to a certain extent decision-making these domains are not clearly identified and discerned in educational management texts. As for integration between the two dimensions, the discrepancy is even wider. Implementation of ideas presented here requires certain recalibrations of management courses. This can be on done on the more individual level or preferably on a more general, or common macro level.

On the individual level an instructor, when explaining a certain subject to students, ought to ask himself questions that were presented earlier in the paper: Is a particular body of material that I explain descriptive or normative? Is there a clear differentiation between the two aspects? If there any integration, and what particular mode of integration do I apply? Are the descriptive and prescriptive parts equally robust? In the event a textbook used by a professor does not provide sufficient answers to these questions, he or she should be cognizant of this and take additional measures towards identifying and resolving pertinent issues. Obviously an instructor does not need to explicitly articulate to an audience the presence and utilization of the two approaches at all times but he or she should constantly keep them in mind. On a more generalized level, change can be made in textbooks and other instructor's materials. It is important that educational texts provide faculty with a clear representation of, on the one hand, the distinction between normative and descriptive spheres and, on the other, their connection.

\section{References}

Adler, P., \& Borys, B. (1996). Two types of bureaucracy: enabling and coercive. Administrative Science Quarterly, 41(1), 61-89. http://dx.doi.org/10.2307/2393986

Alderfer, C. P. (1969). An empirical test of a new theory of human needs. Organizational Behavior \& Human Performance, 4(2), 142-175. http://dx.doi.org/10.1016/0030-5073(69)90 004-X

Bastardi, A., Uhlmann, E. L., \& Ross, L. (2011). Wishful thinking: Belief, desire, and the motivated evaluation of scientific evidence. Psychological Science, 22(6), 731-732. http://dx.doi.org/10.1177/0956797611406447

Bell, D. E., Raiffa, H., \& Tversky, A. (1988). Decision making: Descriptive, normative, and prescriptive interactions. New York: Cambridge University Press. http://dx.doi.org/10.1017/C BO9780511598951

Blake, R., \& Mouton, J.S. (1985). The Managerial grid III. Houston, TX: Gulf.

Blau, P. M., \& Schoenherr, R. A. (1971). The structure of organizations. New York: Basic Books.

Burns, T., \& Stalker, G. (1961). The management of innovation. London: Tavistock.

Daft, R. (2014). Management (14th ed.). Mason, OH: Cengage Learning. 


\section{Macrothink}

Deming, W. E. (1986). Out of crisis. Cambridge, MA: M.I.T. Center for Advanced Engineering Studies.

Devlin, J. F., Gwinne, A. L., \& Ennew, C. T. (2002). The antecedents of service expectations. The Service Industries Journal, 22(4), 117-136. http://dx.doi.org/10.1080/714005102

Donaldson, T., \& Dunfee, T. W. (1994). Toward a unified conception of business ethics: integrative social contracts theory. Academy of Management Review, 19(2), 252-284. http://dx.doi.org/10.5465/AMR.1994.9410210

Evans, J. R., \& Lindsay, W. M. (2008). Managing for quality and performance excellence. Mason, OH: Cengage Learning.

Fiedler, F. (1967). A theory of leadership effectiveness. New York: McGraw-Hill.

Gitlow, H., Oppenheim, A., Oppenheim, R., \& Levine, D. (2005). Quality management: Tools and methods for improvement. New York: McGraw-Hill

Fukukawa, K. (2003). A Theoretical review of business and consumer ethics research: Normative and descriptive approaches. The Marketing Review, 3(4), 381-401. http://dx.doi.org/10.1362/146934703771910035

Hackman, J. R., \& Oldham, G. R. (1980). Work redesign. Reading, MA: Addison-Wesley.

Hersey, H., Blanchard, K., \& Johnson, D. (2013). Management of organizational behavior: Leading human resources (10th ed.). Upper Saddle River, NJ: Prentice Hall.

Hochschild, A. (1983). The managed heart: Commercialization of human feeling. Berkeley, CA: University of California Press.

Hofstede, G. (1985). The interaction between national and organizational value systems. Journal of Management Studies, 22(4), 389-398. http://dx.doi.org/10.1111/j.1467-6486.1985. tb00001.x

House, R. J. (1996). Path-goal theory of leadership: Lessons, legacy, and a reformulated theory. Leadership Quarterly, 7(3), 323-252. http://dx.doi.org/10.1016/S1048-9843(96)90024 $-7$

House, R. J., Hanges, P. J., Javidan, M., Dorfman, P. W., \& Gupta, V. (Eds.). (2004). Culture, leadership, and organizations: The GLOBE study of 62 societies. Thousand Oaks, CA: Sage.

Jayaram, J., Ahire, S. L., \& Dreyfus, P. (2010). Contingency relationships of firm size, TQM duration, unionization, and industry context on TQM implementation - A focus on total effects. Journal of Operations Management, 28(4), 345-356. http://dx.doi.org/10.1016/j.jom. 2009.11.009

Kohlberg, L. (1976). Moral Stages \& Moralization: The cognitive-development approach. In T. Lickona (Ed.), Moral development \& behavior: Theory, research, and social issues (pp. 31-55). New York: Holt, Rinehart \& Winston.

Laroche, M., Kalamas, M., Cheikhrouho, S., \& Cezard, A. (2004). An assessment of the 
dimensionality of should and will service expectations. Canadian Journal of Administrative Sciences, 21(4), 361-375. http://dx.doi.org/10.1111/j.1936-4490.2004.tb00351.x

Mansfield, R. (1973). Bureaucracy and centralization: An examination of organizational structure. Administrative Science Quarterly, 18(4), 77-88. http://dx.doi.org/10.2307/2392200

Maslow, A. (1954). Motivation and human personality. New York: Harper \& Row.

McClelland, D. (1985). Human motivation. Glenview, IL: Scott, Foresman.

McGregor, D. (1960). The Human side of enterprise. New York: McGraw-Hill.

Meirovich, G., \& Romar, E. (2007). The difficulty in implementing TQM in higher education instruction: The duality of instructor/student roles. Journal of Quality Assurance in Education, 14(4), 324-336. http://dx.doi.org/10.1108/09684880610703938

Meirovich, G. (2006). Quality of design and quality of conformance: contingency and synergistic approaches. Journal of Total Quality Management and Business Excellence, 17(2), 205-220. http://dx.doi.org/10.1080/14783360500450640

Meirovich, G., \& Little, L. (2013). The delineation and interactions of normative and predictive expectations in customer satisfaction and emotions. Journal of Consumer Satisfaction, Dissatisfaction \& Complaining Behavior, 26, 40-54.

Mintzberg, H. (1971). Managerial work. Management Science, 18(2), B97-B110. http://dx.doi. org/10.1287/mnsc.18.2.B97

Morris, J. A., \& Feldman, D. C. (1996). Managing emotions in the workplace. Journal of Managerial Issues, 9(3), 257-274.

Parasuraman, A., Zeithaml, V., \& Berry, L. (1985). A conceptual model of service quality and its implications for future research, Journal of Marketing, 49(4), 41-50. http://dx.doi.org/10.2 $307 / 1251430$

Parasuraman, A., Zeithaml, V., \& Berry, L. (1988). Servqual: A multiple-item scale for measuring consumer perceptions of service quality. Journal of Retailing, 64(1), 12-40.

Robbins, S., De Cenzo, D., \& Coulter, M. (2015). Fundamentals of Management (9th ed.). Upper Saddle River: Prentice Hall.

Robbins, S., \& Coulter, M. (2013). Management (12th ed.). Upper Saddle River, NJ: Prentice Hall.

Rossouw, G. J., \& van Vuuren, L. J. (2003). Modes of managing morality: A descriptive model of strategies for managing ethics. Journal of Business Ethics, 46(4), 389-402. http://dx.doi.org/10.1023/A:1025645402328

Rosenthal, S. B., \& Buchholz, R. A. (2000). The empirical-normative split in business ethics: A pragmatic alternative. Business Ethics Quarterly, 10(2), 399-408. http://dx.doi.org/10.2307/ 3857883 
Salmela, M. (2005). What is emotional authenticity? Journal for the Theory of Social Behavior, 35(3), 209-230. http://dx.doi.org/10.1111/j.1468-5914.2005.00273.x

Sharma1, S. (2014). Emotions in the workplace: Understanding the relationship between emotional labor and employee job satisfaction. International Journal of Organizational Behaviour \& Management Perspectives, 3(2), 965-971.

Simon, H. (1991). Bounded rationality and organizational learning. Organization Science, 2(1), 125-134. http://dx.doi.org/10.1287/orsc.2.1.125

Sitkin, S. B., Sutcliffe, K. M., \& Shroeder, R. G. (1994). Distinguishing control from learning in Total Quality Management: A contingency approach. Academy of Management Review, 19(3), 537-564. http://dx.doi.org/10.5465/AMR.1994.9412271813

Thompson, A., Peteraf, M., Strickl, A., \& Gamble, J. (2014). Crafting and executing strategy (18th ed.). New York: McGraw Hill/Irwin.

Thompson, A., Strickl, A., \& Gamble, J. (2013). Crafting and executing strategy (17th ed.). New York: McGraw Hill/Irwin.

Vareman, N. (2008). Norms and descriptions. Decision Analysis, 5(2), 88-99. http://dx.doi.org/10.1287/deca.1080.011

Victor, B., \& Cullen, J. (1988). The Organizational bases of ethical work climates. Administrative Science Quarterly, 33(1), 101-125. http://dx.doi.org/10.2307/2392857

Volokh, E. (2003). The mechanisms of the slippery slope. Harvard Law Review, 116(4), 1026-1137. http://dx.doi.org/10.2307/2392857

Voss, G. B., Parasuraman, A., \& Grewal, D. (1998). The roles of price, performane, and expectations in determining satisfaction in service exchanges. Journal of Marketing, 62(4), 46-61. http://dx.doi.org/10.2307/1252286

Vroom, V. H. (1964). Work and motivation. New York: Wiley.

Vroom, V., \& Jago, A. (1988). The new leadership: Managing participation in organizations. Englewood Cliffs, NJ: Prentice Hall.

Werhane, P. H. (1994). The normative/descriptive distinction in methodologies of business ethics. Business Ethics Quarterly, 4(2), 175-181. http://dx.doi.org/10.2307/3857489

\section{Copyright Disclaimer}

Copyright for this article is retained by the author(s), with first publication rights granted to the journal.

This is an open-access article distributed under the terms and conditions of the Creative Commons Attribution license (http://creativecommons.org/licenses/by/3.0/). 